\title{
A propósito de la Reestructuración de la Facultad de Educación
}

\section{JUAN MANUEL PEREA ESPITIA Jefe de Programa Matemáticas y Física}

La educación para el siglo XXI indudablemente que requiere soluciones audaces para que los conocimientos impartidos y construidos en los centros educativos, Universidades y colegios, estén más próximos a la realidad de acuerdo a los avances logrados en el campo de la ciencia y la tecnología. También, dichos conocimientos deben sere la base para ayudar a formar el recurso humano (en nuestra Facultad el Licenciado) que construirá el futuro de la sociedad y evitar de esta manera que las instituciones educativas sigan aisladas y a la zaga de los procesos de desarrollo de las comunidades.

Consciente de nuestra condición de país en vía de desarrollo, creo que no se trata de formar en nuestras Facultades recursos humanos con el fin de competir con los países desarrollados en el campo de la ciencia y la tecnologia, en donde han logrado grandes avances, sino que por el contrario, además de impartir conocimientos, debemos crear conciencia acerca de nuestra capacidad para adaptar, elaborar y transferir tecnología así como para propender por desarrollos acordes con nuestra realidad con el fin de adquirir nuestra propia identi-dad y luego trascender dentro del contexto mundial. No es que se pretenda, por ejemplo, ignorar los avances logrados en campos como la Informática y la Robótica, sino que debe buscarse desarrollos y aplicaciones tecnológicas con el fin de optimizar y perfeccionar procesos de nuestra realidad, como puede ser en el campo de los recursos naturales, recursos que nos colocan en ventaja con respecto a muchos de los países desarrollados.

De otra parte, la actual organización económica en los países avanzados, impone un nuevo concepto de capital y de recursos para la producción de riqueza. Concretamente, los conocimientos se han convertido en un verdadero capital y en el recurso más valioso para la producción de bienes. Dentro de esta perspectiva la Universidad, y en particular la Facultad de Educación, como responsable de la formación de quienes construirán, aplicarán o impartirán conocimiento para ponerse al servicio de la comunidad, enfrenta un reto realmente dificil, tal vez como nunca antes; mantenerse permanentemente actualizada y modernizada para responder a las exigencias de la sociedad; pues somos conscientes que los conocimientos vigentes en nuestros días son de naturaleza bastante diferente a los de hace unos años. Además, la dinámica es tal que unas décadas atrás, alguien con capacidad de mano de obra calificada tenía muchas más posibilidades laborales que 
hoy, pero ahora, la mano calificada ha venido perdiendo valor en la misma medida en que la automatización de los procesos de producción se va perfeccionando. Por otro lado, y también al mismo ritmo del perfeccionamiento tecnológico, los individuos con ideas innovadoras, con capacidad creativa, encuentran más y mejores oportunidades.

Debemos tomar conciencia que los cambios en el conocimiento actualmente son acelerados y no como en décadas anteriores en que los aprendizajes concretos hacían a un individuo competente porque el ritmo de cambios era tan lento que una persona podía vivir 50, 606 más años sin observar cambios fundamentales. Hoy las cosas son mury distintas. Un pequeño ejemplo basta parta darnos una idea de los vertiginosos cambios que deber afrontar el hombre contemporáneo. A mediados de la década del $\mathbf{5 0}$ se le preguntó a John Von Neumann, uno de los investigadores de frontera en cibernética por esa época, que cuántos computadores creía él que iba a haber al terminar el siglo. Después de hacer un estimativo de las grandes instituciones en el mundo que estarían en capacidad de adquirir un computador, contestó que al finalizar el siglo habria entre 10 y 15 computadores. Menos de 25 años más tarde se habían construido cantidades inmensas de pastillas de silicio que reducian los costos de producción y aumentaban las capacidades de los computadores a niveles insospechados, y el número de ellos ascendía a decenas de millones. Hoy no sólo los encontramos en todo nuestro entorno cotidiano, sino que ya no es asunto de ciencia ficción los computadores que aprenden a seguir las órdenes de sus propietarios o los que le devuelven la movilidad a los parapléjicos.

Después de estas consideraciones se puede concluir que la reestructuración de la Facultad debe tener como objetivos:

1. Responder a los retos científicos y tecnológicos del momento con el diseño y actua- lización de currículos que propendan por el desarrollo de la creatividad en sus estudiantes, futuros educadores de la juventud.

2. Responder a la sociedad con un perfil de educador que no sólo posea buenos conocimientos sino que además sea capaz de desarrollar nuevas ideas, nuevos conocimientos, para adaptarse a un mundo cambiante siempre nuevo e insospechado; es decir, gestor de nuevos procesos educativos y no simple repetidor.

3. Adecuar y captar los recursos necesarios (salas de informática, biblioteca, laboratorios, ayudas didácticas, etc.) para impartir una formación menos teórica y más práctica con aplicaciones y soluciones al entorno.

Finalmente, lo anterior sólo se puede materializar si la reestructuración se da paralela a un plan de inversión que permita actualizar y aumentar los títulos de la biblioteca, modernizar los laboratorios, adquirir equipos con nuevas tecnologías, vincularse a redes de información, ampliar y fortalecer el laboratorio de informática, etc., porque de lo contrario la reestructuración se queda en el nivel de las definiciones y denominación de dependencias pero no en el nivel operativo para el cambio. 